\title{
Exclusion of prognostic coronary disease in LV dysfunction using late gadolinium enhancement CMR
}

\author{
Alexandra Thompson ${ }^{1 *}$, Jenifer Crilley', Jerry J Murphy ${ }^{1}$, Douglas Wilson², Pali Hungin², Ahmet Fuat ${ }^{1,2}$ \\ From 18th Annual SCMR Scientific Sessions \\ Nice, France. 4-7 February 2015
}

\section{Background}

In new diagnoses of left ventricular (LV) systolic dysfunction it is important to exclude coronary artery disease (CAD) as the cause. Cardiac magnetic resonance imaging using late gadolinium enhancement (LGE CMR) highlights fibrosis from ischaemia or infarcts in a subendocardial distribution. Many consider that the absence of LGE indicates an absence of significant CAD. The evidence for this is debatable, with variable sensitivities depending upon the definition of CAD, the patient population, and the use of proximal coronary artery imaging (MRCA). We strived to ascertain the utility of LGE CMR to exclude prognostic CAD.

\section{Methods}

We retrospectively reviewed a cohort of patients attending a district general hospital who underwent both X-ray angiography and LGE CMR since 2006. Records of those with European criteria for LV systolic dysfunction (LVEF $<50 \%$ or LVEDVI $\geq 97 \mathrm{~mL} / \mathrm{m}^{2}$ ) on CMR or transthoracic echo were analysed. The presence and extent of subendocardial LGE was recorded with the 17 segment model. The degree of coronary stenosis at $\mathrm{X}$-ray angiography was assessed visually and significant disease defined as stenosis of the LMS $\geq 50 \%$, or proximal LAD $\geq 75 \%$, or $\geq 70 \%$ in two main coronary vessels.

\section{Results}

A total of 116 patients were included. Mean age was 64 years and $78 \%$ were male. Mean LVEF was $40 \%$. The prevalence of prognostic CAD was high at $47 \%$. Subendocardial LGE detected prognostic CAD with a sensitivity

${ }^{1}$ Cardiology, Darlington Memorial Hospital, Tyne and Wear, UK Full list of author information is available at the end of the article of $100 \%$ (95\% CI, 94 to $100 \%)$ with no false negative results.

\section{Conclusions}

LGE CMR reliably excludes prognostic CAD in patients with LV systolic dysfunction.

Table 1 Diagnostic parameters of LGE CMR to predict prognostic CAD

\begin{tabular}{cc}
\hline & $\begin{array}{c}\text { Performance of LGE CMR (95\% Confidence } \\
\text { Interval) }\end{array}$ \\
\hline $\begin{array}{c}\text { Prevalence of prognostic } \\
\text { CAD }\end{array}$ & $47 \%$ (38 to 57\%) \\
\hline Sensitivity & $100 \%$ (94 to 100\%) \\
\hline Specificity & $44 \%(32$ to $58 \%)$ \\
\hline Positive Predictive Value & $62 \%(51$ to $72 \%)$ \\
\hline Negative Predictive Value & $100 \%(87$ to $100 \%)$ \\
\hline False Omission Rate & $0 \%(0$ to $13 \%)$
\end{tabular}

LGE CMR, Cardiac magnetic resonance with late gadolinium enhancement sequences; $C A D$, Coronary artery disease. Results confirmed by exact methods.

Table 2 Diagnostic performance of LGE CMR to predict prognostic CAD

\begin{tabular}{cccc}
\hline CMR LGE & \multicolumn{2}{c}{ X-ray angiogram } & Total \\
\cline { 2 - 3 } & $\begin{array}{c}\text { Prognostic CAD } \\
\text { present }\end{array}$ & $\begin{array}{c}\text { Prognostic CAD } \\
\text { absent }\end{array}$ & \\
\hline $\begin{array}{c}\text { Subendocardial LGE } \\
\text { present }\end{array}$ & 55 (TP) & 34 (FP) & 89 \\
\hline $\begin{array}{c}\text { Subendocardial LGE } \\
\text { absent }\end{array}$ & $0(\mathrm{FN})$ & $27(\mathrm{TN})$ & 27 \\
\hline Total & 55 & 61 & 116 \\
\hline
\end{tabular}

CAD, Coronary artery disease; CMR, Cardiac magnetic resonance; LGE, Late gadolinium enhancement; TP, True positive; FP, False positive; FN, False negative; $\mathrm{TN}$, True negative. 


\section{Funding}

N/A.

\section{Authors' details}

${ }^{1}$ Cardiology, Darlington Memorial Hospital, Tyne and Wear, UK. ${ }^{2}$ School of

Medicine, Pharmacy and Health, Durham University, Durham, UK.

Published: 3 February 2015

doi:10.1186/1532-429X-17-S1-P187

Cite this article as: Thompson et al:: Exclusion of prognostic coronary disease in LV dysfunction using late gadolinium enhancement CMR.

Journal of Cardiovascular Magnetic Resonance 2015 17(Suppl 1):P187.

Submit your next manuscript to BioMed Central and take full advantage of:

- Convenient online submission

- Thorough peer review

- No space constraints or color figure charges

- Immediate publication on acceptance

- Inclusion in PubMed, CAS, Scopus and Google Scholar

- Research which is freely available for redistribution

Submit your manuscript at www.biomedcentral.com/submit 